\title{
Model-based prediction of fusimotor activity during active wrist movements
}

\author{
Bernard Grandjean ${ }^{1}$, Marc A Maier ${ }^{1,2^{*}}$ \\ From Twenty Second Annual Computational Neuroscience Meeting: CNS*2013 \\ Paris, France. 13-18 July 2013
}

\section{Introduction}

Muscle spindles, whose activity is determined by muscle length changes and by fusimotor drive (i.e. $\gamma$-drive), provide critical information about movement position and velocity [1]. However, task-dependent fusimotor drive remains largely unknown [2], since no fusimotor neurons have ever been recorded during active, voluntary upper limb movements, whether in animals nor in humans. So far an estimation of $\gamma$-drive could only be obtained through an indirect inference of fusimotor activity from observed muscle spindle activity. Our aim was to model the effect of $\gamma$-drive on muscle spindles and to simulate voluntary wrist movements for which the spindle responses are empirically known.

\section{Methods}

Our conceptually simple computational model (an adaptation of [3]) allows for a direct quantification of $\gamma$-drive. A forward calculation predicts spindle responses based on time-varying $\gamma$-drive and muscle length changes. This computational model thus links a biomechanical (musculo-tendon) wrist model to length- and $\gamma$-drive-dependent transfer functions of group Ia and group II muscle spindles. These transfer functions were calibrated

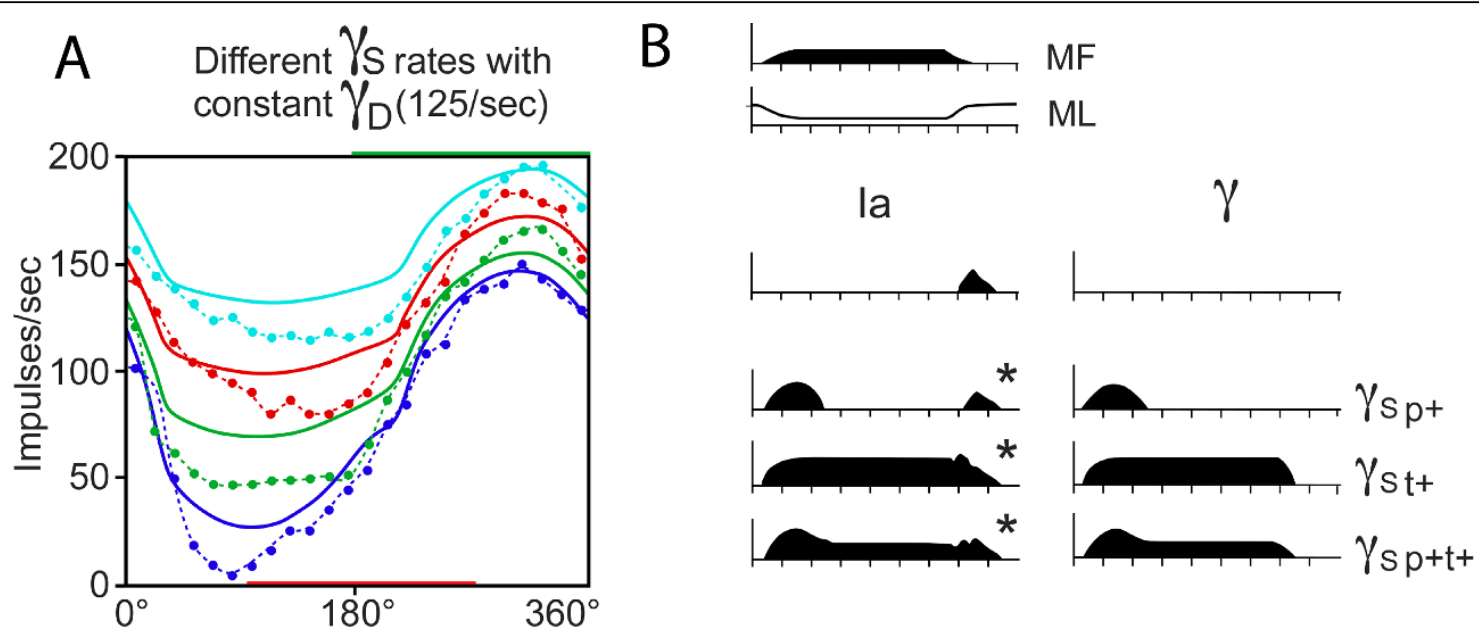

Figure $1 \mathrm{~A}$. Fit between passive [4](dotted lines) and simulated (lines) la responses during sinusoidal stretch under constant $\gamma_{\mathrm{D}}$-drive $(125 \mathrm{~Hz})$ and 4 different rates of $\gamma_{\mathbf{s}}$-drive (top to bottom: 125, 75, 50, $0 \mathrm{~Hz}$ ). B. Simulated la responses (left column) during active muscle contraction for 4 different $\gamma_{s}$-drives (right column): no, phasic, tonic and phasic-tonic drive. ${ }^{*}$ indicates simulated responses similar to empirically observed la responses [5].

\footnotetext{
* Correspondence: marc.maier@parisdescartes.fr

${ }^{1}$ CNRS UMR 8194, Université Paris Descartes, Sorbonne Paris Cité, Paris, F-

75006, France

Full list of author information is available at the end of the article
} 
(Figure 1A) with extant data from passive movements in the cat $[4]$.

\section{Results}

Our simulations suggest that (i) empirically observed muscle spindle activity profiles can to a large part be explained by a strongly task-dependent $\gamma$-drive (Figure 1B), (ii) observed differences between individual muscle spindle response profiles can be explained by a corresponding variability in the $\gamma$-drive (Figure 1B), and (iii) observed phase advance of spindle responses can to a large part be explained by appropriate $\gamma$-drive.

\section{Conclusion}

Our simulation predicts that $\gamma$-drive is strongly modulated and task-dependent and that appropriate $\gamma$-drive can explain many empirically observed aspects of group Ia and II muscle spindle responses during active movements.

\section{Author details}

${ }^{1}$ CNRS UMR 8194, Université Paris Descartes, Sorbonne Paris Cité, Paris, F75006, France. ${ }^{2}$ Univ Paris Diderot, Sorbonne Paris Cité, Paris, F-75013,

France.

Published: 8 July 2013

\section{References}

1. Prochazka A: Proprioceptive feedback and movement regulation. Handbook of Physiology Exercise: Regulation and Integration of Multiple Systems Bethesda, MD; Am Physiol Soc, sect. 12, part I, p. 89-127.

2. Windhorst U: Muscle spindles are multi-functional (Technical comment). Brain Res Bull 2008, 75:507-508.

3. Maltenfort MG, Burke RE: Spindle model responsive to mixed fusimotor inputs and testable predictions of beta feedback effects. J Neurophysiol 2003, 89(5):2797-2809.

4. Hulliger M, Matthews PBC, Noth J: Static and dynamic fusimotor action on the response of la fibres to low frequency sinusoidal stretching of widely ranging amplitudes. J Physiol (Lond) 1977, 267:811-836.

5. Flament D, Fortier PA, Fetz EE: Response patterns and post-spike effects of peripheral afferents in dorsal root ganglia of behaving monkeys. J Neurophysiol 1992, 67:875-889.

doi:10.1186/1471-2202-14-S1-016

Cite this article as: Grandjean and Maier: Model-based prediction of fusimotor activity during active wrist movements. BMC Neuroscience 2013 14(Suppl 1):016.

\section{Submit your next manuscript to BioMed Central} and take full advantage of:

- Convenient online submission

- Thorough peer review

- No space constraints or color figure charges

- Immediate publication on acceptance

- Inclusion in PubMed, CAS, Scopus and Google Scholar

- Research which is freely available for redistribution

Submit your manuscript at www biomedcentral com/submit 